\title{
THE CONTRIBUTION OF SECURITY TO WELL-BEING
}

\author{
Jonathan Herington
}

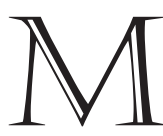

ANY PEOPLE'S LIVES involve grave risks to their well-being. Their incomes are vulnerable to layoffs and economic downturns. Their housing status is at the mercy of capricious landlords. Their health is especially threatened by disease and injury. For some people these risks mature in ways that make them obviously worse off: they are actually deprived of their income, home, or health. But even those who are lucky enough to never actually be deprived of these goods seem badly off. A life of grave vulnerability and insecurity, even if it never actually involves being deprived of important goods, strikes most of us as undesirable. Not only do we want to enjoy the good life, we want to enjoy it securely.

Unfortunately, it is difficult to explain precisely how security contributes to an individual's well-being. Of course, security is instrumentally good. The absence of risks to our future enjoyment of prudential goods is, ex ante, indicative that we will actually enjoy those goods. But can security be basically good? Can risks to prudential goods diminish the goodness of a life even if, ex post, the individual is never actually deprived of those goods? To clarify the question, consider three different lives. ${ }^{1}$

Ava, Bao, and Carol are counterparts whose lives have been equivalent up until their thirtieth birthday. On their birthday they receive an echocardiogram, which results in the following set of divergent circumstances. Ava's test indicates that she has a congenital heart defect that, in any given year, has a 30 percent chance of causing her sudden death. The results of the test are accurately reported to her, and she immediately apprehends the grave risk to her life. Bao's test also indicates that she possesses the congenital heart defect, but owing to a mix-up in the lab, she is told that she has a clean bill of health. No one, including Bao, is aware of the grave 
risk to her life. Carol's test indicates that her heart is in fine working order, and this is accurately reported to her.

Now suppose that, despite the overwhelming odds, Ava, Bao, and Carol all die on their fortieth birthday, the victims of an automobile accident. Suppose further that, between their thirtieth and fortieth birthdays, Ava, Bao, and Carol live externally indistinguishable lives: they experience the same set of circumstances, make the same choices, enjoy the same successes and failures. While Ava's and Bao's congenital defect could have cut short their lives, it luckily did not. Was Ava's life as good as Bao's? Was Bao's as good as Carol's?

One set of views suggests that only Ava is worse off. On these views, Bao's and Carol's lives are equivalently good because the unrealized and unknown risk to Bao alters neither her external circumstances nor her experience of those circumstances. ${ }^{2}$ On the other hand, Ava's awareness of the risk to her life, even though it does not alter her circumstances or choices, undermines her subjective experience of those circumstances. In sum, because "fear itself is something to be dreaded" Ava's lack of subjective security makes her worse off than Bao and Carol. ${ }^{3}$ Thus, on this view, while objective security is not prudentially valuable, subjective security contributes directly to the well-being of individuals.

Many, however, are tempted by a more robust connection between security and well-being. ${ }^{4}$ On this view, Carol's life is superior to Bao's life because the mere risk of harm that Bao suffers seems to directly undermine her well-being. Certainly, given a choice between Bao's and Carol's lives, many of us would prefer the security of Carol's (even knowing that their lived experiences would be identical). Bao might still be better off than Ava, but the presence of subjective security does not erase the undesirability of her fragile existence. For many of us it is hard to shake the intuition that objective security contributes directly to the well-being of individuals. Several authors have attempted to justify this intuition. Finkelstein, for instance, claims that risk frustrates a desire to be secure, and hence even unrealized and unknown risks harm their victims. ${ }^{5}$ Likewise, Pettit's account of modally robust goods at first glance seems to imply that risks to a good can undermine the enjoyment of its modally robust counterpart. ${ }^{6}$

2 Arneson, "Disadvantage, Capability, Commensurability, and Policy," 346; Goodin and Jackson, "Freedom from Fear"; Perry, "Risk, Harm, Interests, and Rights."

3 Waldron, "Safety and Security," 469.

4 Finkelstein, "Is Risk a Harm?”; John, "Security, Knowledge and Well-Being”; Selgelid, “The Value of Security."

5 Finkelstein, "Is Risk a Harm?"

6 Pettit, The Robust Demands of the Good. 
Finally, John has argued that risks to one's vital needs undermine an individual's capacity to make and pursue reasonable plans. ${ }^{7}$ Taken together these arguments suggest that objective security may be basically good for individuals, according to at least some popular theories of well-being.

I disagree. In this paper, I argue for the view that only subjective security contributes directly to individual well-being. Moreover, I deepen this account by showing that we need to distinguish between the contribution of (i) our beliefs about the security of prudential goods and (ii) our affective responses to the security of prudential goods. The paper proceeds in five parts. In section 1, I argue that the traditional distinction between objective and subjective security elides a more useful distinction between fact-relative, belief-relative, and affective senses of security. In the remainder of the paper, I investigate the prudential value of security in the context of four common understandings of well-being: as positive hedonic states, as the satisfaction of desires, as the possession of objective goods, and as the exercise of our distinctive capacities. In section 2, I explore the connection between affective security and hedonistic conceptions of individual well-being. I argue that the affect of security is a plausible hedonistic good, and that neither belief-relative nor fact-relative security are necessary conditions for affective security to contribute to individual well-being. In section 3, I explore the contribution of desires for security. I argue that, on actual desire accounts, it is difficult to see how the unknown satisfaction of a desire for security benefits an individual, and on an ideal desire account, it is implausible that we should desire the fact-relative security of a good given full information about whether we would actually enjoy that good. In section 4, I move on to consider the relationship between security and the possession of modally robust goods. I show that while the modal robustness of some goods may be constitutive of individual well-being this cannot explain the value of security per se. Finally, in section 5, I explore the claim that the absence of risks to our "vital needs" is necessary to be able to form reasonable plans, ultimately arguing that belief-relative security, rather than fact-relative security, is necessary in order to form rational plans. Hence, on any theory that takes rational planning or achievement to be basically good, belief-relative security is also basically good. Thus, I conclude that we have good reason to reject the view that fact-relative security contributes to individual well-being. Nonetheless, we should endorse the claim that both belief-relative security and the affect of security are basically good according to theories of well-being that endorse the prudential value of positive hedonic states, rational planning, or achievement. 


\section{PRELIMINARIES}

Roughly put, an individual's security with respect to some prudential good (e.g., happiness, physical health) is simply their probability of enjoying at least that good. It is, in this sense, a measure of the extent to which they can rely upon enjoying that good. But this simple definition obscures a great deal of nuance that is relevant to the contribution of security to individual well-being. Let me clarify some important considerations.

First, while the word "security" has a close association with freedom from physical violence, I am interested in the security of a much broader range of prudential goods. ${ }^{8}$ One can talk coherently of the security of binary goods (e.g., the probability that $S$ will at least enjoy "sufficient clean water") or increments of a scalar good (e.g., the probability that $S$ will at least enjoy "an annual income of $\$ 20,000 ")$. Likewise, we can talk of the security of a good at a particular moment in time (e.g., the probability that $S$ will at least enjoy "sufficient clean water tomorrow"), or the continuous enjoyment of that property over time (e.g., the probability that $S$ will enjoy "sufficient clean water each day for the next twenty years"). The security of certain prudential goods may be especially valuable-e.g., the security of one's freedom from violence or the security of one's social bases of respect. ${ }^{9}$ However, I am interested in whether the security of prudential goods in general contributes to individual well-being. Most discussions of the harm of risk focus on the imposition of risks and benefits by other agents, such as your neighbor playing with explosives in their basement or a friend gifting you lottery tickets. ${ }^{10}$ These examples muddy the waters. Plausibly, if I impose a risk on you then I wrong you-even if that risk never harms you-because such an imposition disrespects your status as a moral and political equal. ${ }^{11} \mathrm{But}$ not all risks involve disrespect from other agents, and so our intuitions about cases of agent-imposed risk mix judgments about wrongful conduct with judgments about individual well-being. Since I am concerned with the prudential disvalue of risk per se, I will frame each example case around risks imposed by the world, not by other agents.

Second, the traditional distinction between objective and subjective security obscures a more useful distinction between fact-relative security, belief-relative

8 For a discussion of the "pure safety" account of security, see Waldron, "Safety and Security," 461-66.

9 Waldron, "Security as a Basic Right (after 9/11)"; Wolfendale, "Moral Security."

10 See Finkelstein, "Is Risk a Harm?” 968; Arneson, "Disadvantage, Capability, Commensurability, and Policy," 346. 
security, and the affect of security. The fact-relative security of some prudential good $G$ for an individual $S$ at some time $t$ is the objective probability that $S$ will enjoy $G$, given the state of the world at $t .^{12}$ This is the chance at $t$ that $S$ will enjoy $G$. Note that, because the chance of enjoying $G$ is conditional on the state of the world at $t$, fact-relative security is determined by the content of the possible futures of the actual world. ${ }^{13}$ This distinguishes the security of a good from the robustness of that good, i.e., the probability that $S$ would enjoy $G$, not just in the possible futures of the actual world at $t$, but also given some relevant set of changes to the actual world at $t .^{14}$

The belief-relative security of some good $G$ for an individual $S$ at some time $t$ is $S$ 's subjective probability of enjoying $G$, given her beliefs at $t$. This is $S$ 's credence at $t$ that $S$ will enjoy $G .{ }^{15}$ Importantly, both fact-relative and belief-relative security should be intelligible according to most contemporary interpretations of probability. For instance, one could believe that claims about objective probability are claims about the "long-run" frequencies of events, inherent "propensities" of the world, or the credences that an idealized agent would adopt given access to the best account of the laws of nature. ${ }^{16}$ Likewise, one could believe that subjective probabilities are beliefs about objective probabilities, degrees of belief, or some admixture of the two. In my view, the debate between these interpretations of probability is orthogonal to the claim that security contributes to well-being. The frequentist can consider the belief-relative security of an event

Talk of fact-relative security implicitly assumes that at least some facts about the future are unsettled, but some contend that all of the facts about the future are determined by the current state of the world and a set of deterministic laws. See Schaffer, "Deterministic Chance?" If the world does indeed have deterministic laws then fact-relative security would be easy to characterize: the probability will be either zero or one, dependent on whether or not the agent enjoys the good in the actual world. I think, however, that we have good reason to think that we ought to treat the future as "open” (Barnes and Cameron, "The Open Future”). This may be because of an irreducible metaphysical property that creates indeterminacy (for a survey, see Gillies, "Varieties of Propensity"), indeterminacy over the "best account" of the laws of the universe, or the inclusion of indeterministic laws within the "best account" of the universe (Lewis, "Humean Supervenience Debugged"). In this respect, I think we have good reason to suppose that fact-relative security is a meaningful concept.

13 Possible futures of a world $w$ at $t$ are those possible worlds that are "historically indistinguishable" from $w$ at $t$. See Feldman, Doing the Best We Can, 18-19.

14 Pettit, The Robust Demands of the Good and "Freedom and Probability"; List, "Republican Freedom and the Rule of Law."

15 Note that $S$ may or may not have an explicit belief about the probability of enjoying $G$. For instance, in some cases, she may explicitly believe that "the probability of being employed at the end of the year is 80 percent," while in other cases her credence that she will be employed at the end of the year will be implied by her total set of beliefs.

For a summary of the competing interpretations, see Mellor, Probability, chs. 3-4. 
$X$ to be the individual's belief about the long-run frequency of $X$, and fact-relative security to be the actual long-run frequency of $X$. Likewise, the Bayesian can consider belief-relative security to be the individual's credence that $X$, and fact-relative security to be the credence that $X$ adopted by some idealized observer. ${ }^{17}$ In this paper I will adopt a broadly Bayesian perspective, but all that I say here can be applied, mutatis mutandis, to other accounts of probability.

The affect of security is an emotional state of calm assurance. Almost all of us can identify with the fearfulness of the lost toddler, the anxiety of the job seeker in a bad market, or the "pit-of-the-stomach" unease of the patient with the suspect mole. Likewise, we are familiar with the felt quality of calm that occurs when we are reunited with our parent, offered a job, or told that the mole was benign. Indeed, the word "security" has long been associated with an affect of calm assurance. Consider that the Latin securitas (literally "freedom from care") was often used among Roman and early medieval scholars to denote a state of "impassiveness (or) calmness." 18 Likewise, in many Stoic and Epicurean writings of the Roman period, securitas captures the Epicurean concept of ataraxia (á $\left.\tau \alpha \rho \alpha \xi^{\xi} \alpha\right)$, understood as: "a state of contentment and inner calm that arises from the thought that one has or can easily get all that one needs, and has no reason to be afraid of anything in the future." ${ }^{19}$ Importantly, the affect of security is not a cognitive state like a belief or an attitude, but rather a felt quality of tranquility. It is the directly apprehended experience of freedom from anxiety, rather than the belief that one is safe or secure.

Finally, we can distinguish between an ex ante and ex post perspective from which to judge whether security contributes to individual well-being. The security of prudential goods is of obvious relevance when making ex ante judgments about which life we would prefer, or who is subject to greater disadvantage. ${ }^{20}$ Since the constant risk of catastrophe severely diminishes Ava's and Bao's expected well-being, one has strong reason, ex ante, to prefer Carol's life. I am interested, however, in our ex post judgment of whether an insecure life is all things considered as good as a secure life. Moreover, security may be basically good for the individuals who possess it, or merely instrumental to the enjoyment of some properly basic good. In what follows, I interpret something to be basically good for an individual if (i) it is a constituent of individual well-being or (ii) it is necessary to the enjoyment of constituents of individual well-being. For instance,

Lewis, "A Subjectivist's Guide to Objective Chance."

18

Hamilton, Security, 51; Herington, "The Concepts of Security, Liberty, Fear and the State," 23-24.

Striker, “Ataraxia," 100.

Wolff and de-Shalit, Disadvantage, 65-72. 
according to some objective list theories of well-being, "achievements" are constitutive of individual well-being. ${ }^{21}$ And while we might not take the ability to form and revise plans to be a constituent of well-being per se, the formation and execution of a plan is a necessary component of an achievement. In this sense, our planning capacity can be basically good for us, even if it fails to be a constituent of well-being.

In what follows I explore whether fact-relative, belief-relative, or affective security can be basically good for individuals. I do so by exploring whether and how four broad approaches to well-being-hedonic, desire-satisfaction, objective-list, and perfectionist theories-might analyze the prudential value of security. Ultimately, I conclude that arguments for the prudential value of fact-relative security fail to go through on any of these accounts, but that both affective and belief-relative security can be prudentially valuable on a wide range of theories of well-being.

\section{HEDONISM AND THE AFFECT OF SECURITY}

We begin with the relationship between security and hedonistic constituents of well-being. Hedonistic accounts of well-being hold that $S$ is better off than $S^{*}$ if and only if $S$ experiences more happiness (or less suffering) than $S^{*}$. Different accounts of hedonism differ with respect to whether "happiness" refers to a "felt quality" of pleasure or a more complex cognitive attitude. ${ }^{22}$ Likewise some hedonists evaluate lives according to the happiness experienced in each moment, whereas others evaluate lives as a whole. Uniting these accounts, however, is a commitment to the view that well-being is determined by an individual's phenomenal perception: that $S$ may be benefited, or harmed, by something only if "it affects her experiences in some way." ${ }^{23}$

According to this account of hedonism, it seems likely that the affect of security would be a constituent of individual well-being. Recall that the affect of security is best understood as a feeling of calm assurance (ataraxia), and that this affective state has a storied history as a distinctive constituent of well-being. For Epicurus, ataraxia was, alongside freedom from bodily pain (aponia), one of the two components of happiness. ${ }^{24}$ For later hedonists, ataraxia assumed even more importance, prompting Cicero to describe securitas as the "object of

Bradford, Achievement; Griffin, Well-Being, 64.

Bramble, "The Distinctive Feeling Theory of Pleasure"; Feldman, Pleasure and the Good Life.

Bramble, "A New Defense of Hedonism about Well-Being," 88.

Striker, “Ataraxia," 99. 
supreme desire." 25 One need not be an Epicurean, however, to acknowledge the contribution that the affect of security makes to individual well-being. Modern hedonists are also cognizant of the harm wrought by anxiety about the future. For Bentham, the "pain of anticipation" that accompanies uncertainty with respect to prudential goods is a "peculiar evil" that may be as disvaluable as the actual loss of those goods. ${ }^{26}$ These views provide one explanation for why Ava's life seems impoverished, despite being externally indistinguishable from the lives of Claire and Bao. We suppose that Ava experiences anxiety or fear at the thought of sudden death, and these feelings undermine her well-being by depriving her of a positive hedonic state. Importantly, one need not commit to a view about whether ataraxia has a particular "felt quality," or whether it is valuable because the individual possesses some pro-attitude toward it. Neither does one have to be a strict hedonist to endorse the value of the affect of security. All that needs to be the case is that, inter alia, positive hedonic states (however understood) are partly constitutive of an individual's well-being. We therefore have good reason to suspect that the affect of security directly contributes to an individual's well-being on accounts of well-being that take it to be composed, at least partially, by positive hedonic states.

Importantly, there is no necessary connection between the affect of security and either belief-relative or fact-relative security. Ordinarily, of course, individuals are likely to experience the affect of security only if they also possess belief-relative security with respect to central prudential goods. But as those with anxiety disorders understand, one can have belief-relative security and yet lack affective tranquility. Likewise, the undocumented migrant taking antianxiety medication may experience the affect of security, even while they lack belief-relative security with respect to their freedom, employment, or housing status. While there are obvious cognitive inputs into affective responses, the affect of security is precisely the thing that is felt rather than the beliefs that might inspire that feeling.

Is the affect of security sufficient to improve an individual's well-being? Or is it simply a component of a more complex bearer of hedonistic value? One might object that a lack of security is often hedonically valuable, and so the affect of security cannot be sufficient to improve individual well-being. As aficionados of extreme sports, theme park rides, and horror movies know well, a felt quality of risk can be exhilarating, and this suggests that the affect of security may simply be a means to some more fundamental contributor to individual well-being. There are two potential responses to this concern. The first is to note that these examples involve fear that is both superficial and momentary. It is superficial insofar

25 Rothschild, "What Is Security?” 61.

26 Bentham, "Principles of the Civil Code," ch. viI. 
as it does not typically involve the kind of existential dread that accompanies the fear that one might be attacked, diagnosed with a terminal illness, or unable to provide for one's family. The feeling of risk is normally experienced as valuable when it is either the product of simulated risk (e.g., the rush from watching a horror film), or the risk to one's basic goods is relatively small (e.g., the thrill of a flutter on Cup day). The appeal of this kind of insecurity is that it is borne of relatively inconsequential risks. Moreover, such insecurity is momentary insofar as it does not provide a permanent backdrop against which the agent lives their life. Those subject to persistent risks to their basic needs do not describe that risk as exhilarating. ${ }^{27}$ At best they adopt an affect of security despite those risks. More often they describe the feeling of risk as an oppressive component of their experience. The hedonic value of fleeting moments of insecurity therefore seems predicated on the possession of a more general, and deeply felt, affect of security.

A second concern may be that the contribution of the affect of security to an individual's well-being is dependent on the reasonableness of the individual's affect. The affect of security often fails to neatly track fact-relative security, and is heavily influenced by a complex set of psychological and sociological facts. This is troubling insofar as some individuals seem to possess a "false sense of security" and hence systematically endanger themselves. On the view just sketched, these unreasonably secure individuals would be better off than the reasonably fearful, but, so the objection goes, this has the contribution backward! It is those who respond appropriately to the existence of threats who are better off, insofar as they can take action to avoid threats of death or severe deprivation.

I think this objection is confused, for two reasons. First, the claim is that the possession of an affect of security at $t$ is associated with an all-things-considered decrease in $S$ 's well-being at some future point in time $t_{2}$. Yet this does not show that $S$ is all-things-considered worse off at $t$, only that she is likely to be all-things-considered worse off at $t_{2}$. That the affect of security is constitutive of $S$ 's well-being at $t$ is compatible with the fact that this is associated with a decrease in her future well-being. Second, this objection appears to conflate possessing inappropriate beliefs with possessing inappropriate affects. While it may be advantageous to have fitting beliefs with respect to your security so that you may plan carefully and responsibly, it does not seem advantageous to fear fittingly. ${ }^{28}$ Given fear's well-demonstrated impact on cognitive reasoning and decision-making, it would appear to be best to possess fitting beliefs but unfitting affective responses. A cool, calm, calculated approach is highly likely to maximize future well-being.

28 I will explore the effect of belief-relative security on planning in section 5 . 
Given these considerations, hedonistic accounts have a ready explanation for the judgment that only Ava's life is worse than Carol's (while Bao's is equivalently good). The affect of security is a positive hedonic state, and neither belief-relative nor fact-relative security is necessary for this state to contribute to individual well-being. And while there is certainly an ex ante instrumental connection between fact-relative security, belief-relative security, and one's possession of the affect of security, there is nothing necessary about this connection. Therefore, those who are tempted to endorse the view that both Ava and Bao are worse off than Carol must turn elsewhere to justify the claim that fact-relative security is basically good.

\section{A DESIRE FOR SECURITY}

I turn now to desire-satisfactionist theories of well-being. At its most basic, desire satisfactionism holds that your well-being consists in the satisfaction of at least some of your desires. More precisely, $S$ is better off than $S^{*}$ if $S$ 's desires (of a suitable sort) are satisfied (in the relevant sense) to a greater extent than $S^{*}$ 's desires are satisfied. ${ }^{29}$ As we shall see, precisely which kinds of desires-actual or idealized, self-regarding or holistic — contribute to individual well-being is an open question. Likewise, there is controversy over whether a desire for $X$ is satisfied by the mere existence of the state of affairs $X$, the belief that $X$, or the simultaneous combination of $X$ and a belief that $X{ }^{30}$ Different combinations of answers to these controversies make for more or less plausible conceptions of desire satisfactionism. And unfortunately, the theories that best make sense of a desire for fact-relative security are also the least plausible conceptions. Instead, the best conceptions seem to support the value of belief-relative security.

To begin with, the desire satisfactionist can readily make sense of the value of the affect of security, since if an individual desires to feel secure (to experience ataraxia), then they are benefited by the affect of security. Likewise, if an individual desires the absence of the affect of security (at a particular time and in a particular way) then that individual is benefited by its absence. And since most of us, most of the time, have a desire for the affect of security, we are benefited by experiencing it. This is no surprise.

More interestingly, one might appeal to desire satisfactionism to motivate

This is a very general account of desire satisfactionism. A full account will identify the relative contribution to individual well-being of (i) satisfying a greater number of desires and (ii) satisfying stronger desires.

30 Heathwood, "Desire Satisfactionism and Hedonism”; Lin, “The Subjective List Theory of Well-Being." 
the value of fact-relative security, and so vindicate the judgment that Carol is better off than both Ava and Bao. Some have claimed that fact-relative risks to personal goods directly undermine well-being because they frustrate a desire to be free from risk per se. Claire Finkelstein holds a version of this view, which she calls the "Risk Harm Thesis": insofar as we prefer to have a lower rather than higher chance of being harmed, merely being subject to a risk of harm is a "setback to a person's most fundamental interests." ${ }^{\text {"11 }}$ It is plausible to presume that many of us possess a preference to be free from risk per se-few people regret paying premiums for insurance policies that never mature, or purchasing additional safety features in cars that never experience an accident. If the satisfaction of desires is constitutive of well-being, and it is true that many of us possess a desire to be free from risk, then fact-relative security may be basically good. Unfortunately, Finkelstein's view is plausible only on the most general description of desire satisfactionism. Once we are more precise about the kinds of desires that contribute to well-being, the Risk Harm Thesis faces a dilemma between (i) embracing an implausible actual-desire theory or (ii) embracing an ideal-desire theory that is unlikely to treat desires for fact-relative security as coherent. I explore each horn of this dilemma in turn.

\subsection{Actual Desires for Security}

The first horn of the dilemma is embracing the actual-desire account. On this view, $S$ is benefited by a state of affairs $X$ (at a time $t$ ) if and only if $S$ actually desires $X$ (at $t$ ) and it is the case that $X$ (at $t$ ). Moreover, on the standard account of this view, $S$ is benefited by $X$ regardless of whether or not $S$ believes that $X$ obtains. The value of fact-relative security is easy to appreciate from this perspective. Since it is plausible that many people would prefer (at each moment in time) to be free of risk, the fact-relative security (at each moment in time) of prudential goods (enjoyed in the future) satisfies that desire and so makes those individuals better off. Unfortunately, the actual-desire account is implausible, for two widely known reasons.

First, satisfying many of our actual desires seems contrary to our good. For instance, the actual-desire account implies that satisfying an instrumentally confused desire benefits individuals, even if satisfying that desire frustrates the individual's pursuit of goods they take to be intrinsically valuable. Consider an individual who desires to drink a glass of liquid, because they take that glass to contain a delicious chardonnay, when in fact it is filled with an awful sherry. While they are radically mistaken about whether their desire for the liquid will 
satisfy a more basic desire, satisfying their instrumental desire for the liquid in the glass benefits them according to the actual-desire account. ${ }^{32}$

Second, placing to one side the plausibility of appealing to actual desires, allowing unknown satisfactions of a desire to improve an individual's well-being entails some implausible judgments. Consider the following case:

Suppose I spy a very attractive stranger on the subway. Despite being uninterested in a romantic relationship, I desire that the stranger find me attractive. Suppose further that, unbeknownst to me, the stranger has been stealing glances at me and is also attracted to me (and perhaps has the same desire I do). We both remain stony-faced, and leave the train at different stops, never to be made aware of our mutual attraction. ${ }^{33}$

I find it implausible that, in this case, I am made better off by the unknown satisfaction of my desire to be seen as attractive. While it is true that I get what I want, in some sense, I never appreciate or experience the satisfaction of that desire. The satisfaction of the desire is alien to me. Perhaps the unknown satisfaction of that desire is good, impartially speaking, but the sting of dissatisfaction will linger for me. While not everyone will view these kinds of cases as a decisive objection to traditional desire satisfactionism, the burden appears to be on advocates of the Risk Harm Thesis to explain how the unknown satisfaction of a desire to be free from risk contributes to our well-being in the absence of the belief that I am free from risk.

Interestingly, one solution to the problem of unknown satisfactions is to adopt "subjective desire satisfactionism." ${ }^{34}$ On these views, $S$ is benefited by $X$ (at $t$ ) if and only if $S$ desires that $X$ (at $t)$ and $S$ believes that $X$ (at $t$ ). Because your well-being is determined by which states of affairs you believe have been realized, your prudential good is not alienated from your experience in the same way as traditional desire satisfactionism. But on this view, while the individual's desire may be for fact-relative security, it is belief-relative security that is the well-being-conferring object. Thus, while subjective desire satisfactionism would make sense of the judgment that Ava is worse off than Bao, it would not support the judgment that Carol is better off than Bao. On this view, belief-relative security, but not fact-relative security, is basically good.

32 For a defense of the actual-desire account from this problem, see Heathwood, "Desire Satisfactionism and Hedonism."

33 Thanks to Rosa Terlazzo for suggesting this example.

34 Heathwood, "Desire Satisfactionism and Hedonism”; Lin, “The Subjective List Theory of Well-Being.” 


\subsection{Idealized Desires for Security}

The other horn of the dilemma facing the Risk Harm Thesis is to endorse an ideal-desire account. On ideal-desire accounts, the desires that are relevant to an individual's well-being are those that she would possess were she to be fully rational and fully informed about the world, including the outcome of her choices, the phenomenal experience of those outcomes, and the ways in which particular satisfactions would interact. ${ }^{35}$ This is a more attractive theory than the actual-desire account, insofar as it eliminates the problem of instrumental desires: our individual, having full access to the relevant information, is no longer benefited by drinking the awful sherry. Yet as others have noted, if one is fully informed about the world, then one must have knowledge of whether or not a risk of harm at $t_{1}$ actually will result in harm at $t_{2}{ }^{36}$ For instance, in the process of idealizing Bao's desires, we would have to consider her desires were she to know both that she possesses a congenital heart defect and that it would not actually affect her life in any way. Yet when the outcome of a risk is transparent to the agent, the claim that the agent would possess a desire to be free from that particular risk becomes less plausible. There seems to be little reason for a fully informed, ideally rational version of Bao to desire that Bao is free of a risk that the advisor knows will not materialize. Once again, the burden of proof seems to shift to the proponent of the Risk Harm Thesis: this time to give some compelling rationale for why an ideal advisor might value fact-relative security.

Note, however, that there are clear reasons why an ideal advisor might desire belief-relative security for their advisee. As I will explore in section 5 , belief-relative security may be a necessary condition for rational planning. Some advisors may desire for their advisees the ability to make rational life plans because it involves an exercise of their will. Others may value planning insofar as making and executing plans is constitutive of what it means to achieve our goals rather than fulfilling them fortuitously. These kinds of complex rationales for a desire are available to ideal-advisor theorists, even if the advisees do not actually desire cognitive coherence or planning, so long as they resonate with the core values of their advisee. In this respect, the ideal-desire account can claim that belief-relative security, but not fact-relative security, is basically good.

Thus, the proponent of the desire-satisfaction explanation of the value of fact-relative security faces a dilemma. If they embrace an actual desire view then they must (i) defend an intuitively implausible theory and (ii) show why un-

Sobel, "Subjectivism and Idealization." 
known satisfactions of actual desires can contribute to an individual's well-being. If they embrace an informed-desire view then risk preferences cease to be plausible. Importantly, the proponent of desire satisfactionism does not face this dilemma with respect to belief-relative security.

\section{OBJECTIVE-LIST THEORIES AND MODALLY DEMANDING GOODS}

I now turn to consider two recent accounts of the value of fact-relative security. Both rely on objectivist accounts of well-being. On the objectivist account of well-being, at least some of the things that are good for an individual are good for her regardless of her attitude toward those goods. More precisely, $S$ is better off than $S^{*}$ if $S$ possesses to a greater degree than $S^{*}$ those goods $\left\{g_{1}, g_{2}, \ldots g_{n}\right\}$ that are the basic constituents of individual well-being. Different accounts of objectivism differ with respect to the goods that constitute the basic constituents of well-being. At least some candidate goods include pleasure, knowledge, achievement, moral virtue, friendship, and self-respect. ${ }^{37}$ Furthermore, there is a split between "objective-list" theories that simply enumerate the set of goods that constitute well-being, and "perfectionist" theories that attempt to explain the content of the list by reference to the kinds of creatures that human beings are. Importantly, objectivists need not be insensitive to an individual's judgments about their own good. Most acknowledge that, while it is good for you to possess the relevant objective goods, it is better for you to value or take pleasure in your possession of those goods. ${ }^{38}$ In this respect, most objective-list theories can readily make sense of the value of affective and belief-relative security. Insofar as pleasure or the satisfaction of desires is on the objective list, we can readily explain why Ava is worse off than Bao and Carol. But because objectivist accounts do not solely rely upon individuals' attitudes toward their lives, they also appear to be a natural way of arguing for the prudential value of fact-relative security.

One such argument might appeal to the concept of "modally robust" goods, those "rich" goods (e.g., friendship) whose existence depends upon the enjoyment of a "thin" good (e.g., care), not only in the actual world but in a salient class of non-actual circumstances. ${ }^{39}$ For instance, in order to enjoy the good of friendship, one must enjoy another person's care and concern, not just in the

37 Fletcher, "A Fresh Start for the Objective-List Theory of Well-Being," 214; Griffin, Well-Being, 67; Hooker, "The Elements of Well-Being."

38 Kagan, "Well-Being as Enjoying the Good"; Fletcher, "A Fresh Start for the Objective-List Theory of Well-Being," 215-17.

39 Pettit, The Robust Demands of the Good; Southwood, "Democracy as a Modally Demanding Value." 
actual circumstances but across a wide range of ways in which your circumstances could be different (such as if you were poor or you were a vegetarian). If this other person would stop caring for you were you to lose all your money, then they are not your friend. This general pattern seems to apply to a wide range of goods, including freedom, democratic self-rule, and the rule of law. ${ }^{40}$ If fact-relative security of a thin good (e.g., care) captures the robustness of your enjoyment of that good across a wide range of possible futures, then it appears to be a necessary condition for the enjoyment of the modally robust counterpart (e.g., friendship). Hence, some might claim that Bao is worse off than Carol because, while Bao may actually enjoy care from her loved ones, this care will fail to be robust throughout the possible futures.

It would, however, be a mistake to try to explain the disvalue of risk by reference to modally demanding goods. First, security and robustness capture two distinct modal conditions. As I have defined it, fact-relative security is determined by future subjunctives (i.e., possible futures), whereas robustness is concerned with true counterfactuals (i.e., possible worlds). ${ }^{41}$ To possess the "thick" good of friendship at $t$ involves facts about whether you would enjoy your friends' care were the world relevantly different at $t$, but to be secure in your friendship at $t$ involves facts about how likely you are to remain friends at some future time $t_{2}$ given the way the world is structured at $t$. Of course, in practice it will often be the case that the security of a good will track the robustness of a good, yet there will also be cases where the two modal qualities come apart. If your friends' care is dependent on your enormous wealth, it may be secure insofar as you are highly unlikely to lose your wealth in the future, but may not be robust insofar as if you were (counterfactually) a pauper your friend would not care for you in the present. ${ }^{42}$ In this respect, we cannot straightforwardly appeal to the value of modally demanding goods in order to claim that fact-relative security is prudentially valuable.

40 Pettit, "Freedom and Probability"; Southwood, "Democracy as a Modally Demanding Value"; List, "Republican Freedom and the Rule of Law."

41 As an anonymous reviewer points out, this distinction is dependent on my stipulated definition of security. Some might be motivated to define individual security as modal robustness, i.e., as the degree of counterfactual change to the actual future such that the individual no longer enjoys the good. This definition might seem to explain the value of fact-relative security (of at least some goods) because robustness (in certain respects) is necessary for the instantiation of modally robust goods. As I discuss below, however, Pettit's account of modally robust goods does not support the value of robustness in general, merely robustness in certain respects.

42 Pettit himself is careful to make this distinction. See Pettit, The Robust Demands of the Good, 258. 
Second, even if we were to define security as modal robustness, the class of modally demanding goods is small, and their instantiation does not require robustness in general. Pettit, for instance, suggests that modally demanding goods are "rich" goods such as love, respect, and honesty that are instantiated by the robust possession of the "thin" goods of care, restraint, and truth telling, respectively. ${ }^{43}$ Moreover, these thin goods need not be robust across all possible changes, merely a subset of relevant changes. For instance, in order to enjoy the love of someone else, one need only enjoy their care across changes in their disposition toward you, not a more general set of possible changes. For Pettit, the value of modally demanding goods is that they involve protection from the arbitrary will of others - they instantiate a particular relation between oneself and others that is intrinsically valuable. ${ }^{44}$ Thus, while the fact-relative security of certain goods, in certain respects may directly contribute to one's well-being, Pettit's conception of a modally demanding good does not establish that fact-relative security is prudentially valuable in general.

\section{PERFECTIONISM, RISK, AND PLANNING}

A second objectivist argument for the value of security might appeal to a broadly perfectionist account of well-being. Such accounts include many of the goods found in objective list theories (pleasure, knowledge, etc.), but ground their prudential value in the relation of those goods to individuals' exercise of their distinctively human capacities. In this respect, they often place a special emphasis on goods related to an individual's agency: knowledge acquisition, life planning, and the achievement of our rational aims. ${ }^{45}$ This has prompted an argument that fact-relative security is prudentially good because it is necessary to the formulation of reasonable plans. This proposal has recently been pursued by Stephen John, who argues that when we are exposed to grave risks to our "vital needs" we lack a crucial component required to form reasonable plans. ${ }^{46}$ Since John claims that we have an objective interest in being able to form reasonable plans, fact-relative security of our vital needs is basically good. I argue, however, that perfectionist accounts of the value of planning support the prudential value of belief-relative security, rather than fact-relative security.

43 Pettit, The Robust Demands of the Good, 108.

44 Pettit, The Robust Demands of the Good, 121.

45 Hurka, Perfectionism.

46 For John, an individual "has a vital need for $X$, if and only if she will fail to achieve a normal level of physical functioning if she goes without X." John, "Security, Knowledge and Well-Being," 74. 
John draws upon Michael Bratman's theory of planning agency in order to make his case for the view that "physical security ... is a constituent element of well-being." ${ }^{47}$ Roughly put, John's argument is as follows. If an individual $S$ lacks the capacity to make "reasonable" plans, then $S$ 's well-being is diminished. If $S$ cannot reasonably presuppose her vital needs, then $S$ lacks the capacity to make reasonable plans. If $S$ lacks fact-relative security with respect to her vital needs, then $S$ cannot reasonably presuppose her vital needs. ${ }^{48}$ Therefore, if $S$ lacks fact-relative security with respect to her vital needs, then $S$ 's well-being is diminished. As we shall see, this argument is confused about the way in which risks undermine the noninstrumental value of planning. A tighter consideration of these questions suggests that it is belief-relative risks that directly diminish individual well-being.

To see why, consider that, on Bratman's view, plans are commitments to pursue a particular end and do not require a full specification of the intermediate steps one will (optimally) take in order to realize that end. ${ }^{49}$ Thus, if I plan to grade exams this afternoon, I need not specify all of the steps I will take to realize that end. Instead, I may be content to commit to doing the things necessary to meet that goal, without specifying precisely how I will ultimately realize that goal. Importantly, for my plan to count as rational it must be "means-end coherent," in the sense that if I intend to $\phi$, and believe that $m$ is a necessary means to $\phi$, then I must intend to $m .{ }^{50}$ Moreover, if my intention to $\phi$ is rational, I must believe that $m$ (and all other necessary means to $\phi$ ) will be available to me. Thus, if I intend to grade some exams, and I believe that collecting the exams from the

John, “Security, Knowledge and Well-Being," 76. For Bratman's theory, see Bratman, Intention, Plans and Practical Reason.

John's account of the security of vital needs is couched in terms of possessing the "warrant" for the belief that the agent will continue to meet her vital needs "across the range of plausible futures" ("Security, Knowledge and Well-Being," 73). However, I take this formulation to be equivalent to the fact-relative security of the agent's vital needs. To consider why, note that John is an externalist about justification, such that an individual has the warrant for a belief if "the world ... [is] such that this belief would, in fact, be justified" ("Security, Knowledge and Well-Being," 73). In this respect, we can analyze the warrant for the true belief that $S$ will meet her vital needs across the range of plausible futures as simply the fact that $S$ will meet her vital needs across the range of plausible futures. Moreover, the fact that $S$ will meet her vital needs across the range of plausible futures is extensionally equivalent to the claim that it is objectively certain (or near certain) that $S$ will meet her vital needs. While the probability of a future event can come apart from its robustness tout court (see section 4 ), the robustness of an event across the set of possible futures of the world as it is at $t$ should be read as extensionally equivalent to the probability at $t$ of that event.

Bratman, Intention, Plans and Practical Reason, 3. 
office is a necessary means to grading the exams, I ought to believe that I will be able to collect the exams from the office (and intend to do so). John introduces an additional "reasonability" condition on planning. For John, the reasonableness of a plan is determined by whether the beliefs that the plan presupposes are "likely to be true." 51 Thus, if you intend to $\phi$, and you believe (or presuppose) that $m$ is a necessary means to $\phi$, then your plan is "reasonable" only insofar as $m$ is fact-relatively secure.

The connection between fact-relative security of vital needs and reasonable plans thus becomes apparent. For any plan to $\phi$, one of the necessary means to $\phi$ is that you will survive until you $\phi$. If you are subject to serious fact-relative risks to your vital needs, then you cannot presuppose that you will survive and so cannot make a reasonable plan with respect to any $\phi$. Thus, John claims that individuals with grave risks to their vital needs lack the ability to make reasonable plans. It is this ability to make reasonable plans, not the making of reasonable or rational plans per se, that he claims is constitutive of individual well-being. ${ }^{52}$ John's view contributes much to our understanding of the connection between security and individual well-being, but we ought to reject it for two reasons.

First, fact-relative security is not sufficient to be a planning agent. According to John's view, an individual who is free from risks to their vital needs, but believes that they are at grave risk, will count as being able to form plans. ${ }^{53}$ Yet, this is mistaken. Consider the following case:

Imagine two counterparts, Ava and Dina, who both believe that they possess a congenital heart defect that, in any given year, has a 30 percent chance of causing their sudden death. While it is true that Ava does possess such a defect, Dina is not actually afflicted and has a great deal of evidence that this is the case. Owing to their beliefs, both Ava and Dina make only the shortest and most cursory of plans, and while their lives are filled with moments of happiness, they fail to achieve much at all. They both die at the same age, having lived externally indistinguishable lives.

On John's view, Ava is better off than Dina merely by virtue of the fact that she possesses the warrant for the belief that she will meet their vital needs. Yet what prevents both agents from forming and pursuing complex plans is that they believe that there are grave risks to their vital needs. While it is true that Dina could

51 John, "Security, Knowledge and Well-Being," 77.

52 John, "Security, Knowledge and Well-Being," 77.

53 John claims that "what matters to successful planning is not our conscious belief that we are secure, but rather that there is warrant for the belief presupposed in our planning that we will continue to achieve physical functioning" ("Security, Knowledge and Well-Being," 80). 
make reasonable plans were she more responsive to the facts, she is no more able than Ava to actually make reasonable plans given her beliefs. Plans must be made with the beliefs and presuppositions that we actually have, and it is of no direct benefit to you that were you to, counterfactually, presuppose your vital needs, you would be warranted in doing so.

Second, the fact-relative security of vital needs is not necessary to enjoy the good of being a planning agent. John claims that being a reasonable planning agent is valuable because if your plans are based upon warranted presuppositions (or beliefs) you will be more successful at pursuing your aims. ${ }^{54}$ Of course, reasonable plans will be instrumental to a good life, insofar as agents who adopt plans based upon warranted presuppositions will be more likely, ex ante, to fulfill their ends. Unfortunately, our noninstrumental interest is in being a rational, not reasonable, planning agent. ${ }^{55}$

Consider that there are three potential ways in which being a planning agent might make a noninstrumental contribution to well-being, and none require being a reasonable agent in John's sense. The first noninstrumental account holds that planning agents are better off by virtue of the fact that this satisfies an interest in understanding their own actions. ${ }^{56}$ On this view, planning to $\phi$ is valuable because it entails the belief that you will $\phi$, and thus contributes to your "self-knowledge," i.e., your knowledge about the kind of agent that you are. ${ }^{57}$ As should be obvious, self-knowledge is unique in that the conditions for obtaining the warrant for the beliefs are all internal to the agent: my plan to $\phi$ does not need to be based on externally warranted presuppositions in order for me to know that I intend to $\phi$. Thus, regardless of whether this position is tenable as an account of planning's contribution to our well-being, it does not require that an agent possess fact-relative security of their vital needs.

The second noninstrumental account holds that plans are constitutive of certain kinds of intrinsically valuable activities. ${ }^{58}$ Consider, for instance, the value of achieving something. ${ }^{59}$ In order to achieve an end, as opposed to merely en-

54 Specifically, John claims that our interest is "in being able to function as a reasonable planner" and that "one way in which plans can fail to be reasonable is when they are based on beliefs which are unlikely to be true (even if the agent is unaware that they are unlikely to be true)" (“Security, Knowledge and Well-Being," 77).

55 Bratman, "Intention, Practical Rationality, and Self-Governance," 430; Ferrero, "What Good Is a Diachronic Will?"

56 Velleman, "The Possibility of Practical Reason," 717.

57 Velleman, "What Good Is a Will?” 211, and “The Possibility of Practical Reason," 719.

58 Ferrero, "What Good Is a Diachronic Will?" 412-16.

59 See Bradford, Achievement; Griffin, Well-Being, 64-65; Hurka, Perfectionism, 123-28 
joying it, we must have planned and pursued that end: inheriting \$1 million does not count as an achievement, but planning, building, and running a business that generates $\$ 1$ million is an achievement. Indeed, the purposeful pursuit of most life goals (e.g., professional success, loving relationships) is partly constitutive of what we take to be worthwhile about those ends. Importantly, the standard accounts of the value of such achievements do not require that the planning and pursuit of those achievements be based upon warranted beliefs. Rather, the value of achievements is grounded in the exercise of an agent's practical rationality or will. ${ }^{60}$ In this respect, the value is determined by the relationship of the achievement to the individual's agency, rather than the reasonableness of the plans employed to realize it.

The third noninstrumental account holds that plans are constitutive of an agent's "self-governance." 11 This account, favored by Bratman, claims that planning constitutes and maintains the appropriate "Lockean" connections and continuities between the individual time slices of an agent. ${ }^{62}$ By adopting overlapping plans to perform future actions, we constitute a narrative connection between earlier and later versions of ourselves. ${ }^{63}$ Once again, the beliefs that these plans presuppose need not be warranted. The mere fact of believing oneself to be able to $\phi$, and to be able to undertake the necessary means to $\phi$, is what allows the agent to see themselves as a contiguous inter-temporal agent.

On any of these three accounts of the direct contribution of planning to individual well-being, our plans need not be reasonable. Instead, what matters is being a rational planner: being the kind of agent who forms plans that are internally consistent and means-end coherent. ${ }^{64}$ Importantly, being a rational planner requires belief-relative security of our vital needs. In order to make means-end coherent plans, we must believe (or presuppose) that we will possess all of the necessary means to realizing those plans. Ava and Dina are thus unable to make rational plans of any great complexity, since neither believes that it is likely they will be alive to fulfill any plan longer than one to two years. On the other hand, Bao's ability to rationally plan is unaffected by the unknown and unrealized risk she faces. Thus, while it might be true that "reasonable" plans (and hence fact-relative security) are ex ante instrumentally valuable, it is belief-relative security that undergirds the ex post prudential value of being a planning agent.

60 Hurka, Perfectionism, 124-26; Bradford, "The Value of Achievements."

61 Hurka, Perfectionism; Griffin, Well-Being, 66; Scanlon, What We Owe to Each Other, 124.

62 Bratman, "Reflection, Planning, and Temporally Extended Agency" and "Intention, Practical Rationality, and Self-Governance."

63 Ferrero, "What Good Is a Diachronic Will?" 416-19.

64 Bratman, "Intention, Practical Rationality, and Self-Governance," 413. 


\section{CONCLUSION}

Given the foregoing considerations, we ought to abandon the revisionist view that fact-relative security is, in general, ex post prudentially valuable. In some respects, this vindicates a traditional view about security: that a risk of harm cannot itself be a harm, and that it is only the subjective experience of risk that diminishes our well-being. But by engaging deeply with sophisticated attempts to establish the value of fact-relative security, I have hopefully achieved two goals.

First, I have argued that attempts to establish the prudential value of fact-relative security often implicitly rely upon particular theories of well-being, and that once these theories are more explicitly specified, the plausibility of the claims about the value of fact-relative security evaporates. To wit, while it is plausible that some people have desires for fact-relative security, it is unclear how the unknown satisfaction of those desires benefits those individuals. Moreover, on ideal-desire accounts, we struggle to explain why an ideal advisor would desire fact-relative security given full knowledge that their advisee would enjoy the good regardless. And while some objective-list theories may include modally robust goods, and so appear to place value on security, the instantiation of modally robust goods is meaningfully distinct from the fact-relative security of goods. While the fact-relative security of certain "thin" goods (i.e., the care of others) may be correlated with the possession of modally demanding goods (i.e., the love of others), these special cases do not establish that fact-relative security is prudentially valuable in general. Finally, while perfectionist theories might treat rational planning as prudentially valuable, the fact-relative security of our vital needs is neither necessary nor sufficient for rational planning. Of course, ensuring that our enjoyment of prudential goods is secure is ex ante prudentially important because it is instrumental to our future well-being. Moreover, we may have moral or political obligations to ensure that others are not subject to grave risks. ${ }^{65}$ But, once we more precisely specify the theories of well-being that undergird different accounts of its value, we are left with the conclusion that fact-relative security is not ex post basically good for an individual.

Second, I have tried to deepen our understanding of the ways in which subjective security contributes to individual well-being. Disambiguating between affective security and belief-relative security affords the opportunity to show that the experience of security has both hedonic and cognitive benefits. In particular, affective security is ex post prudentially valuable on any theory that takes positive hedonic states to be partially constitutive of an individual's well-being. Belief-relative security, on the other hand, is a plausible bearer of prudential val-

65 Shue, Basic Rights; Perry, "Risk, Harm, Interests, and Rights." 
ue because it is a necessary precondition for formulating rational plans. Since rational planning is held to be prudentially valuable by a wide range of perfectionist, objective-list, and ideal-desire satisfaction theories, belief-relative security appears to be ex post prudentially valuable. This goes beyond the standard explanation of the disvalue of believing oneself to be at risk-which is that such beliefs may engender feelings of fear and anxiety. Instead, we might be able to posit a rational and agency-centered sense in which our lives are diminished by a lack of security. Thus, insofar as being able to exercise our agency is considered a central prudential, moral, and political good, we may have good reason to promote belief-relative security. ${ }^{66}$

Kansas State University jherington@ksu.edu

\section{REFERENCES}

Arneson, Richard J. "Disadvantage, Capability, Commensurability, and Policy." Politics, Philosophy and Economics 9, no. 3 (August 2010): 339-57.

Barnes, Elizabeth, and Ross Cameron. "The Open Future: Bivalence, Determinism and Ontology." Philosophical Studies 146, no. 2 (November 2009): 291-309.

Bentham, Jeremy. "Principles of the Civil Code." In The Theory of Legislation, 1:88-238. London: Trubner and Co., 1843.

Bradford, Gwen. Achievement. New York: Oxford University Press, 2015.

- "The Value of Achievements." Pacific Philosophical Quarterly 94, no. 2 (June 2013): 204-24.

Bramble, Ben. "The Distinctive Feeling Theory of Pleasure." Philosophical Studies 162, no. 2 (January 2013): 201-17.

—. "A New Defense of Hedonism about Well-Being." Ergo 3, no. 4 (2016): 85-112.

Bratman, Michael E. Intention, Plans and Practical Reason. Cambridge, MA: Harvard University Press, 1987.

. "Intention, Practical Rationality, and Self-Governance." Ethics 119, no. 3 (April 2009): 411-43.

66 Thanks to Bruce Glymour, Jon Mahoney, and Rosa Terlazzo for reading early drafts of this paper, and to audiences at the Australian National University and Monash University for helpful feedback. My special thanks also to the anonymous reviewers of this paper, whose careful and kind comments were invaluable. 
_- "Reflection, Planning, and Temporally Extended Agency." Philosophical Review 109, no. 1 (January 2000): 35-61.

Feldman, Fred. Doing the Best We Can. Dordrecht: D. Reidel Publishing, 1986.

- Pleasure and the Good Life: Concerning the Nature, Varieties, and Plausibility of Hedonism. Oxford: Oxford University Press, 2006.

Ferrero, Luca. "What Good Is a Diachronic Will?" Philosophical Studies 144, no. 3 (June 2009): 403-30.

Finkelstein, Claire. "Is Risk a Harm?” University of Pennsylvania Law Review 151, no. 3 (January 2003): 963-1001.

Fletcher, Guy. "A Fresh Start for the Objective-List Theory of Well-Being." Utilitas 25, no. 2 (June 2013): 206-20.

Gillies, Donald. "Varieties of Propensity." British Journal for the Philosophy of Science 51, no. 4 (December 2000): 807-35.

Goodin, Robert E., and Frank Jackson. "Freedom from Fear." Philosophy and Public Affairs 35, no. 3 (Summer 2007): 249-65.

Griffin, James. Well-Being: Its Meaning, Measurement and Moral Importance. Oxford: Clarendon Press, 1986.

Hamilton, John T. Security: Politics, Humanity, and the Philology of Care. Princeton: Princeton University Press, 2013.

Heathwood, Chris. "Desire Satisfactionism and Hedonism." Philosophical Studies 128, no. 3 (April 2006): 539-63.

Herington, Jonathan. "The Concepts of Security, Liberty, Fear and the State." In Security: Dialogue across Disciplines, edited by Philippe Bourbeau, 22-44. Cambridge: Cambridge University Press, 2015.

Hooker, Brad. "The Elements of Well-Being." Journal of Practical Ethics 3, no. 1 (June 2015): 15-35.

Hurka, Thomas. Perfectionism. New York: Oxford University Press, 1996.

John, Stephen. "Security, Knowledge and Well-Being." Journal of Moral Philosophy 8, no. 1 (January 2011): 68-91.

Kagan, Shelly. "Well-Being as Enjoying the Good." Philosophical Perspectives 23, no. 1 (December 2009): 253-72.

Lewis, David. "Humean Supervenience Debugged." Mind 103, no. 412 (October 1994): 473-90.

—. "A Subjectivist's Guide to Objective Chance." In Studies in Inductive Logic and Probability, edited by Richard C. Jeffrey, 2:83-132. Berkeley: University of California Press, 1980.

Lin, Eden. "The Subjective List Theory of Well-Being." Australasian Journal of Philosophy 94, no. 1 (2016): 99-114. 
List, Christian. "Republican Freedom and the Rule of Law." Politics, Philosophy and Economics 5, no. 2 (June 2006): 201-20.

Mellor, D.H. Probability: A Philosophical Introduction. New York: Routledge, 2005 .

Narayan, Deepa, Robert Chambers, Meera K. Shah, and Patti Petesch. "Anxiety, Fear and Insecurities." In Voices of the Poor: Crying Out for Change, 151-75. New York: World Bank, 2000.

Oberdiek, John. "The Moral Significance of Risking." Legal Theory 18, no. 3 (September 2012): 339-56.

Perry, Stephen. "Risk, Harm, Interests, and Rights." In Risk: Philosophical Perspectives, edited by Tim Lewens, 190-209. New York: Routledge, 2007.

Pettit, Philip. "Freedom and Probability: A Comment on Goodin and Jackson." Philosophy and Public Affairs 36, no. 2 (Spring 2008): 206-20.

- The Robust Demands of the Good: Ethics with Attachment, Virtue and Respect. Oxford: Oxford University Press, 2015.

Placani, Adriana. "When the Risk of Harm Harms." Law and Philosophy 36, no. 1 (February 2017): 77-100.

Rothschild, Emma. "What Is Security?" Daedalus 124, no. 3 (Summer 1995): 53-98.

Scanlon, T.M. What We Owe to Each Other. Cambridge, MA: Harvard University Press, 1998.

Schaffer, Jonathan. "Deterministic Chance?" British Journal for the Philosophy of Science 58, no. 2 (June 2007): 113-40.

Selgelid, Michael J. “The Value of Security: A Moderate Pluralist Perspective." In Ethics and Security Aspects of Infectious Disease Control: Interdisciplinary Perspectives, edited by Christian Enemark and Michael J. Selgelid, 27-44. Burlington, VT: Ashgate Publishing, 2012.

Shue, Henry. Basic Rights: Subsistence, Affluence, and U.S. Foreign Policy. Princeton: Princeton University Press, 1980.

Sobel, David. "Subjectivism and Idealization." Ethics 119, no. 2 (January 2009): $336-52$.

Southwood, Nicholas. "Democracy as a Modally Demanding Value." Noûs 49, no. 3 (September 2015): 504-21.

Striker, Gisela. "Ataraxia: Happiness as Tranquility." Monist 73, no. 1 (January 1990): 97-110.

Velleman, J. David. “The Possibility of Practical Reason.” Ethics 106, no. 4 (July 1996): 694-726.

- "What Good Is a Will?" In Action in Context, edited by Anton Leist, 193-215. New York: Walter de Gruyter, 2007. 
Waldron, Jeremy. "Safety and Security." Nebraska Law Review 85, no. 2 (2006): 454-507.

- "Security as a Basic Right (after 9/11)." In Global Basic Rights, edited by Charles R. Beitz and Robert E. Goodin, 207-26. Oxford: Oxford University Press, 2009.

Wolfendale, Jessica. "Moral Security." Journal of Political Philosophy 25, no. 2 (June 2017): 238-55.

Wolff, Jonathan, and Avner de-Shalit. Disadvantage. Oxford: Oxford University Press, 2007. 